\title{
The effect of study abroad on intercultural competence: Results from a longitudinal quasi-experimental study
}

\section{Sybille Heinzmann}

University of Teacher Education Lucerne

Roland Künzle

University of Teacher Education Lucerne

Nicole Schallhart

University of Teacher Education St. Gallen

Marianne Müller

University of Teacher Education Lucerne

\section{Introduction}

Skills in several foreign languages are among the core competencies demanded in today's multicultural, mobile and connected society. The desired skills, however, imply more than learning and mastering abstract linguistic tasks related to a language's structure or vocabulary. Rather, the objective is to develop communicative competence, meaning language learners should acquire the skills necessary to communicate appropriately with people from a variety of cultures. In other words, foreign language teaching must also promote the development of intercultural competence (henceforth IC) and adaptability. Indeed, more recent curricula explicitly require intercultural outcomes (such as intercultural sensitivity, tolerance and openness) in addition to the standard, language-based skills (Council of Europe, 1982; D-EDK, 2013; Ingram \& O’Neill, 1999).

While expanding students' IC, and thus making a substantial contribution to a cooperative coexistence in an increasingly globalised world, is an established goal in foreign language teaching, it is also clear that foreign language lessons per se will not always meet this goal if they do not actively work towards it and if learning opportunities in this area are lacking (Ingram \& O’Neill, 1999, p. 3; Weier, 2009, p. 10). Contact with speakers of the target language (henceforth TL) and representatives of the target culture in the form of study abroad or exchange programs provides such opportunities (Weier, 2009, pp. 10-11). Such programs are often an organizational and financial challenge both for schools and students. It is all the more important, therefore, to evaluate the impact of these programs with respect to different goals (academic goals, foreign language goals, intercultural goals) and to identify key factors contributing to fruitful implementations (Anderson \& Lawton, 2011; Engle \& Engle, 2004; Tarrant, et al., 2014). This requires longitudinal large-scale research including a control group that investigates a broad array of study abroad / exchange programs that differ with regard to some key variables (such as duration, age of participants, accommodation, amount of preparation, etc.). Such studies are still rare up to this date (Anderson \& Lawton, 2011; Tarrant, et al., 2014) and usually work with rather small samples. Furthermore, research on the impact of study abroad on intercultural learning also has to shed some light on the sustainability of study abroad / exchange experiences. Unfortunately, there are very few studies that include a delayed post-test (for exceptions, see Dywer, 2004; Rexeisen, et al., 2008).

\section{Literature Review Research Results}


Although the majority of experts consider contact with TL speakers to be an ideal means to positively influence attitudes and skills in intercultural issues, research on the effects of intercultural contact or study abroad programs has revealed that contact alone is not sufficient to attain positive results. Researchers agree that study abroad programs only contribute to intercultural learning if the students really 'experience' the host culture by truly engaging with host country participants while working or studying (Anderson \& Lawton, 2011, p. 87; Donnelly-Smith, 2009). From the influential contact hypothesis (Allport, 1954) we know that the contact situation must fulfil certain criteria to realistically achieve positive effects in terms of intercultural attitudes. For instance, the individuals involved should share similar interests and have about equal social status. The contact situation should also allow for interaction and should be endorsed by a person of authority (Alexander \& Perl, 2010, pp. 288, 291; Baker, 1992, pp. 107-108; Dörnyei \& Csizér, 2005, pp. 328-329; Hewstone, 1996, p. 327; Leyens, et al., 1994, p. 47; Ogay, 2000, p. 274).

Gardner (1985, p. 85), for instance, found that a four-day excursion to Quebec significantly influenced the intercultural attitudes of Anglophone students and led to an increased interest in learning French. At the same time he points out, however, that interaction alone is not enough to positively influence attitudes, that the kind and amount of interaction are crucially important (Gardner, 1985, p. 86). This is also suggested by a study by Thomas which indicates that accommodation in a host family and joint project work with representatives of the TL improves the intercultural learning (Alexander \& Perl, 2010, pp. 290-291).

In addition to the above-mentioned factors, the duration of the exposure and the motivational and attitudinal starting conditions of the people involved play a role (Engle \& Engle, 2003, p. 9). As far as the ideal length of stay is concerned there are mixed research results. Research suggests that longer programs are associated with greater gains in IC (Dwyer, 2004; Engle \& Engle, 2004; Kehl \& Morris, 2008; Medina-López-Portillo, 2004). Nevertheless, short-term programs have also been shown to have a positive impact on cross-cultural development (Anderson, et al., 2006; Dwyer, 2004; Chieffo \& Griffith, 2004; Donnelly-Smith, 2009). There are even studies which suggest that short excursions, in particular, have the potential to positively affect intercultural attitudes and that a more extended contact with the target group can lead to a renewed deterioration of intercultural attitudes (Gardner 1985, pp. 88, 106; Dörnyei \& Csizér, 2005, pp. 351-352). This may be attributable to the somewhat superficial nature of the cultural immersion in short excursions which may prevent participants from encountering intercultural difficulties or culture shock. In the words of Engle \& Engle (2003, p. 6) such excursions provide new and interesting scenery but not a new environment which is characterized by interaction. As Ogay (2000, pp. 274-277) points out, it is possible that short-term study abroad programs only yield positive effects at first sight and do not really advance intercultural learning since contact with representatives of the other cultural group is not intensive and manifold enough for participants to recognize differences or to encounter intercultural challenges and handle them. It is exactly the culture shock or the experience of unfamiliarity and difficulties that forces exchange students to grow interculturally. As Engle \& Engle (2003, p. 5) put it "gain only comes at the expense of a certain pain".

Research on the influence of longer study abroad programs on the intercultural attitudes of exchange students suggests a different trajectory of attitudinal development. Often study abroad participants have particularly positive intercultural attitudes before travelling to the host country. Once 
they live in the host country, these attitudes tend to decline. Provided they stay in the host country long enough, their intercultural attitudes become more favourable again (Gardner, 1985, pp. 88, 106; Dörnyei \& Csizér, 2005, pp. 351-352). Such a U-shaped development could potentially be explained with differing starting conditions of the participants. In the studies by Gardner (1985) and Dörnyei \& Csizér (2005) which focus on short-term contact, the contact with representatives of the host culture was not freely chosen by the participants. Hence, it is likely that not all the participants were positively disposed towards the pending intercultural exchange and the other cultural group. In the case of longterm study abroad programs, the linguistic and cultural exchange is normally chosen by the participants themselves. It is likely that the intercultural attitudes of these students are positive before they depart. Consequently, it is also more difficult to find positive changes. It may also be that intercultural attitudes are so positive before the actual exchange that they cannot be upheld once the students are confronted with linguistic and cultural challenges in the host country, and that, therefore, cross-cultural attitudes may become less favourable in the beginning of the program.

That the starting conditions of the students play a role in the development of IC is underscored by a study by Hammer (2005) on the short- and long-term effects of AFS activities. The study suggests that interculturally less competent adolescents can profit more from their stay abroad than those who are already interculturally relatively competent before their stay abroad.

While positive effects do not happen automatically as a result of contact but are dependent on a number of factors, such as length of program, amount and kind of contact with representatives of the target culture, social status of the involved groups, the affective starting conditions of the participants, etc., studies comparing the intercultural development of study abroad students with that of a control group convincingly show that study abroad activities indeed have the potential to foster the development of IC (Anderson \& Lawton, 2011; Chieffo \& Griffith, 2004; Williams, 2005). In Kehl \& Morris (2008) study students who were enrolled in a long-term program (one semester) rather than a short-term program (8 weeks or less) also exhibited significantly higher global-mindedness than students on the home campus who plan to study abroad in the future. The fact that many studies found evidence for intercultural gains resulting from study abroad experiences, despite using quite different measurement instruments, argues rather persuasively for the transformational experience of study abroad activities.

\section{Theoretical underpinnings}

Intercultural competence (IC) is a complex, multi-layered and, therefore, also somewhat vague concept. It is not surprising then, that different definitions, terms, models, and operationalizations of the concept exist. A definition which could be shown to be deemed appropriate and useful by a panel of research experts and administrators of intercultural programs states that IC is "the ability to communicate effectively and appropriately in intercultural situations based on one's intercultural knowledge, skills and attitudes" (Deardorff, 2006, p.247). As Deardoff points out this definition is derived from Byram's (1997) work on intercultural communicative competence (ICC) and it will be used as a working definition in this paper.

There are numerous models of IC. Some of them conceptualize IC mainly as a sum of different personality traits such as respect, empathy, flexibility, curiosity, tolerance of ambiguity, etc. (Ruben, 1976). Other models, such as Byram's model (1997) focus on different dimensions of IC (attitudes, 
knowledge, awareness, skills). Again other models are mainly concerned with the developmental character of IC, the best-known among them being Bennett's (1993) developmental model of intercultural sensitivity with its six developmental stages of Denial, Defense, Minimization, Acceptance, Adaptation, and, finally, Integration.

All these theoretical concepts also have their limitations. As Leiprecht (2001, pp. 15-18) points out, general personality traits, such as empathy, tolerance of ambiguity, or flexibility may be necessary components of IC, but they are not enough to cover the construct. Firstly, these general personality traits have to be targeted at specific intercultural issues (e.g. empathy for perceived discrimination and marginalization) in order to function as constituting elements of IC. Secondly, IC also comprises other components such as behavioural components, cognitive components and value-based components (Leiprecht, 2001, p. 18). These feature in multi-dimensional constructs, such as the model of intercultural communicative competence by Byram. A multi-dimensional model, however, raises the question as to how closely related these different dimensions are and to what extent they can be considered constituting elements of a common underlying competence if they are only distantly related. With developmental models of IC the main problem consists in the fact that the different developmental stages were developed theory-driven and up to date, there is no adequate empirical validation of the different stages and their chronology. It is not clear whether all students really go through all of the proposed stages, whether everyone goes through these stages in the same order irrespective of the learning context, origin or age and if the proposed sequence of stages is really appropriate.

Naturally, different models of IC also yield different operationalizations or approaches to measurement. There are numerous instruments for the assessment of IC, such as, for example, the Intercultural Adjustment Potential Scale (ICAPS) (Savicki, et al., 2004), the Assessment of Intercultural Competence (AIC) (Fantini \& Tirmizi, 2006), the instruments from the Intercultural Competence Assessment Project (INCA) (Prechtl \& Lund, 2007), the Intercultural Development Inventory (IDI) (Bennett \& Hammer, 1998), the Multicultural Personality Questionnaire (MPQ) (Van der Zee \& Van Oudenhoven, 2000) or the self-assessment tool Lolipop ${ }^{1}$ Portfolio (Crosbie \& Sudhershan, 2009).

For our own operationalization of the construct of IC we used Byram's (1997) model of intercultural communicative competence as a starting point. This model involves five elements or 'savoirs'. The following four elements were considered in our study:

1. Knowledge (savoir)

2. Critical Cultural Awareness (savoir s'engager)

3. Attitudes (savoir être)

4. Skills of discovery and interaction (savoir apprendre/faire)

We did not include skills of interpreting and relating (savoir comprendre) since this revolves around text-based learning and working with documents which is more relevant for classroom learning. While

\footnotetext{
${ }^{1}$ Language on-Line Portfolio Project
} 
Byram's model integrates foreign language skills in the element 'skills of discovery and interaction' we treated this as a separate dimension since not all intercultural encounters also involve different languages.

\section{The Study}

The present study was carried out in Switzerland among upper secondary school students, many of whom are required to spend some time in a foreign language area as part of their educational degree. As Coleman (1998, p. 174) points out, 'study abroad' is not the most common term used in the European context to refer to this kind of experience. He uses the term 'residence abroad' in his outline of the European perspective. Neither term is entirely appropriate for the present study, though, since it includes both international (TL English) and intra-national stays (TL German or French). While all the participants stayed in an area that is linguistically and culturally different from their place of residence, not all of them went abroad. The multilingual nature of Switzerland with its four national languages offers ideal opportunities for contact with foreign language speakers within its borders. Consequently, we will use the term 'linguistic exchange activities' to talk about the programs in which the participants of this study took place.

The study examined a broad range of linguistic exchange activities at Swiss upper secondary schools which differ with respect to some important features mentioned above (duration, accommodation, affective and linguistic starting conditions, provisions for cultural interaction, etc.) in order to answer the following research questions:

1. What effects do exchange activities have on the development of intercultural competence?

2. What criteria for success can be identified?

The study comprises different formats of exchange activities (exchange with a partner class, traditional language stay with attendance of a language school, internships, culture week, etc.) with different TLs. As upper secondary school students, the participants can be considered having intermediate to upper-intermediate TL competence.

\section{Sample and Design}

The study employed a quasi-experimental longitudinal design with an intervention group consisting of students who took part in an exchange program and a control group consisting of students who did not take part in an exchange program. Both groups were surveyed three times. The students in the intervention group were surveyed before going away (pretest), shortly after the return (posttest) and approximately three months after the return (delayed posttest). The control group was surveyed at the same intervals as the majority of the students who participated in an exchange program. This design allows inferences about both short-term and longer-term effects of linguistic exchange activities.

The sample for the analysis of short-term effects of linguistic exchange activities consisted of 405 upper secondary students from German and French-speaking Switzerland, who participated in an exchange program or went on a language stay (intervention group) and 135 upper secondary students from German and French-speaking Switzerland, who did not participate in an exchange program and did not go on a language stay (control group). The students were between 13 and 20 years-old. The average age was 16 years. Sixty-nine percent were girls and 31\% boys. As far as the nationality of the 
participants is concerned, $73 \%$ were Swiss, 18\% double citizens and 10\% foreigners. Fifty-seven percent were monolingual and $43 \%$ multilingual.

The majority of the participants have a well-educated family background. More than half of the participants come from a family where at least one parent has a university degree. At least one of the parents of another $13 \%$ has an upper secondary school-leaving certificate ${ }^{2}$ as the highest degree. Twenty-four percent indicate the vocational school certificate as the highest degree among their parents and 5\% a secondary school certificate. Six percent of the participants did not know what the highest degree of their parents is.

Table 1 provides an overview of the samples for the posttest (shortly after the return for the intervention group, four to six weeks after the pretest for the control group) ${ }^{3}$.

Table 1: Sample Posttest

\begin{tabular}{|c|c|c|c|c|c|}
\hline & \multicolumn{3}{|c|}{ Intervention group $(\mathrm{n}=405)$} & Control group $(\mathrm{n}=135)$ \\
\hline \multirow{2}{*}{ Target language } & \multicolumn{2}{|l|}{ German or French $(\mathrm{n}=224)$} & \multicolumn{2}{|c|}{ English $(\mathrm{n}=181)$} & $\mathrm{n}=135$ \\
\hline \multirow{2}{*}{ Duration } & $\leq 1$ Month & $>1$ Month & $\leq 1$ Month & $>1$ Month \\
& $\mathrm{N}=164$ & $\mathrm{~N}=60$ & $\mathrm{~N}=132$ & $\mathrm{~N}=49$ & \\
\hline
\end{tabular}

In the following we will characterize the exchange parameters of the students in the intervention group in more detail.

Exchange activities in the traditional sense (with a partner class in the other linguistic/cultural area and bilateral exchange) constitute the minority in our sample. Most participants in our study stem from upper secondary schools which prescribe a three to four week stay in a foreign language (henceforth FL) area for certain classes (e.g. all eighth graders or all bilingual classes). The organization of this stay is usually up to the students with the requirement that no more than two students from the same school go to the same place. The students then look for a language school or an internship themselves. In terms of Engle \& Engle's (2003, pp. 10-13) classification of study abroad programs, the majority of the participants in our study took part in something that is most similar to the 'shortterm study', with the exception that all course work was done in the TL and that the typical type of accommodation was an integrated home stay. ${ }^{4} \mathrm{~A}$ minority of the participants who stayed for a whole semester also participated in something that is close to the cross-cultural immersion program. Quite a few upper secondary schools also offer one-week culture weeks where the entire class lives in a foreign culture for one week and carries out some project work. These latter probably correspond to the Study Tour in Engle \& Engle's (2003) classification. The fact that many upper secondary schools prescribe a FL stay for their students means that most of the participants in our study had to participate in an exchange activity and that not all of them were enthusiastic about this. This guarantees a certain heterogeneity in terms of the sample.

2 This certificate qualifies for university entrance.

${ }^{3}$ This is the sample upon which the analyses of the short-term effects are based.

${ }^{4}$ See Coleman (1998, p. 174) for an elaboration of some basic differences between the prototypical American and European study abroad programs. 
Almost two thirds $(61 \%)$ of the students in the intervention group have attended a language school, $17 \%$ did an internship or voluntary work. Of the fourth $(26 \%)$ that indicated having participated in another type of program, most participated in a traditional exchange with a partner school or partner class in the target area or they attended a regular upper secondary school in the target area. Besides this, the culture-week and au-pair work were mentioned as types of programs by a few participants.

In terms of duration, the exchange activities studied here can be characterized as short-term activities for the most part. Thirty-seven percent of the intervention group participant spent one to two weeks in the target culture, another 38\% three to four weeks, $13 \%$ five to six weeks and 7\% each were away for seven to twelve weeks or for more than twelve weeks. Due to a time frame of two years set for the project, it was not possible to longitudinally evaluate students who spent a whole year in another linguistic/cultural area. There are, consequently, no students in the sample, who participated in a one-year program.

As far as accommodation is concerned, the vast majority $(87 \%)$ of the participants stayed in a host family (home stays). The remaining 13\% stayed in a hotel/youth hostel, a dormitory, a rented apartment, a farm or at a relative's/acquaintance's place.

The students in the control group stem from upper secondary schools whose curriculum does not include linguistic exchange activities or from upper secondary schools who only prescribe a foreign language stay for some of their classes. Students in this group, who reported previous participation in an exchange program, were eliminated from the analyses.

At the time of the delayed posttest the sample has decreased by 36 participants in the control group and 65 participants in the intervention group. This is due to decreasing motivation on the part of the participants to fill in the questionnaire a third time, technical problems with the online tool and lastly, participants leaving the school.

\section{Instruments and data collection}

An online survey on their IC was administered to the participants three times between December 2012 and October 2013. Information on important parameters of the exchange, including the kind of activities undertaken during the exchange, amount of contact with TL speakers, use of the TL during the exchange and type of accommodation, was only collected in the posttest (after the exchange).

The instrument for the assessment of IC was developed by the research team themselves. Many items were inspired by a self-assessment tool of IC called the Lolipop ${ }^{5}$ Portfolio (Crosbie \& Sudhershan, 2009). This is an online language learning portfolio that was developed analogous to the European language portfolio. Unlike the European language portfolio it contains a fully integrated intercultural component with a set of unique 'can-do' statements for the self-assessment of IC. The can-do statements are based on two different theoretical models: Byram's model of intercultural communicative competence, on the one hand and Bennett's model of the development of intercultural sensitivity, on the other hand. While the can-do statements reflect the five different

\footnotetext{
${ }^{5}$ Language on-Line Portfolio Project.
} 
'savoirs' in Byram's model, they are also assigned to six different developmental levels which reflect the stages in Bennett's model. In line with the European language portfolio these six different stages are labelled A1, A2, B1, B2, C1 and C2. ${ }^{6}$

While the can-do statements of the Lolipop Portfolio were an important source of inspiration for the development of our own questionnaire, they were all heavily adapted for our purposes (questionnaire rather than portfolio, cultural target group known, etc.). Firstly, rather than opting for a model which a priori defines certain developmental stages and gauging development by means of items which represent certain developmental stages, we decided to assess different dimensions of IC longitudinally. We assume that the amount of intercultural development will be reflected in the amount of the respondents' agreement/disagreement with items across time.

Another important adaptation concerns the specificity of the items. Most measurement instruments of IC use culture-generic and, therefore, somewhat unspecific items (e.g. tries to understand other people's behaviour) to assess IC. This is problematic to the extent that we cannot know what people or what cultural group(s) respondents are thinking of when responding to such items. As we do not know to what extent IC is a generic competence that an individual possesses irrespective of the target group or target culture or to what extent it is culture-specific this is an important stumbling block. It seems plausible that someone who may be interculturally competent when dealing with French, for example, is not necessarily also interculturally competent when dealing with Chinese, especially if we consider knowledge, intergroup attitudes, and language proficiency as constituting part of a person's IC.

With this in mind, we decided to formulate our items culture-/group-specific, so that we would know what cultural groups the students had in mind when responding to the questionnaire items. On the basis of the destination of most potential participants in our study we focused on the following cultural target groups: Americans, English, Canadians, Australians, French-speaking Swiss, French, German-speaking Swiss, and Germans. The students in the intervention group got a questionnaire with items targeted at the cultural group with which they had contact during their exchange activity. For the students in the control group, who were not in a contact situation with any other cultural group, one of the above-mentioned groups was chosen at random. As a result the questionnaire items certainly had a somewhat different meaning for the participants in the control group than for those in the intervention group.

The questionnaire was developed in the online questionnaire tool Survalyzer and piloted in four school classes (two classes in the control group and two classes in the intervention group). On the basis of the comments from the pilot classes and the experiences during the piloting, the questionnaire was subsequently revised. The questionnaire was developed in German and translated into French by a translation bureau.

For the assessment of the participants' intercultural experiences so far and important information on their exchange program we based ourselves on instruments of INCA (Prechtl \& Lund, 2007), MacFarlane (1997) and Ogay (2000).

\footnotetext{
${ }^{6}$ For more information on the Lolipop Portfolio, see Crosbie and Sudhershan (2009).
} 


\section{Analysis}

Scaling and grouping of questionnaire data.

For the construct 'intercultural competence', scales were generated by means of Rasch analysis where possible. As all items were polytomous with four response categories, the partial credit Rasch model was used (Masters, 1982). The scales were constructed with the data from the pretest. Later the same scaling procedure was used for the posttests in order to make longitudinal comparisons possible. The software RUMM2030 was used to conduct theses analyses (Andrich, et al., 2010).

The dimension, self-assessed language competence will not be analysed further in this article. The dimension knowledge included questions on the participants' knowledge about cultural similarities and differences as well as intercultural communication on the one hand (eight items) and questions about their awareness about their own linguistic and intercultural learning process (four items) on the other hand. No Rasch scale could be constructed for the latter. For the former a Rasch scale could be generated but the scale has a low person-separation index of 0.45 which means that the participants' knowledge is not estimated in a reliable fashion and that the scale does not reliably distinguish between students with a lot of intercultural knowledge and students with little intercultural knowledge. For that reason the dimension knowledge will not be used as a target variable in the ensuing analyses.

The dimension skills comprised 14 items about handling cultural diversity and linguistic as well as cultural challenges. Four items had to be eliminated due to large fit-residuals. The remaining items yielded a one-dimensional Rasch scale. The item "I can compare the culture (e.g. eating habits, clothing, family life, school life, work life, etc.) of $\mathrm{x}$ and y and detect similarities and differences" showed differential item functioning (DIF). Participants who went to a German-speaking area (that is to say French-speaking Swiss) consider themselves to be better at this than participants who went to a French or English-speaking area. Furthermore, there was no clear distinction between the answer categories 'not true' and 'rather not true'. Therefore, these two categories were merged. There was also DIF with regard to the item "I observe how the English behave in different situations and through this I learn more about their habits and way of living". Females have higher values on this which means that they consider themselves to do this more than males. Both these items were separately calibrated for the respective groups for the construction of the Rasch scale.

With regard to the dimension attitudes we distinguished two different subdimensions. The first dimension is comprised of items which primarily target the participants' willingness to engage with people from another cultural and linguistic background and to engage with the intercultural learning process associated with this (willingness, seven items). The second dimension is comprised of items that deal with the feelings that the participants have towards the target area and TL speakers (affect, twelve items). There were too many ill-fitting items and too much differential item functioning (DIF) in both categories for the construction of a Rasch scale. Therefore, a factor analysis was carried out with all the items (Principal axis analysis, Varimax rotation). The measure of sampling adequacy (Kaiser-Meyer-Olkin) was .83. Three items (all of them negatively worded) were eliminated because they had low communalities and correlations with the other items. The scree plot indicated one or three factors. Except for one item ("I try not to judge x prematurely") the willingness items all clearly loaded on one factor. The one ill-fitting item was eliminated and a scale was constructed with all the remaining willingness items (attitudes -willingness). Cronbach alpha is .77 and the corrected item- 
total correlation ranges from .39 to .68 . With the affect items the mapping was less clear. A factor analysis of the affect items alone yields a measure of sampling adequacy of .80 and the scree plot points to two factors. Consequently, two affect scales were generated. Table 2 provides an overview of the scales and their psychometric properties.

Table 2: Scales and their psychometric properties

\begin{tabular}{lll}
\hline Rasch Scales & $\begin{array}{l}\text { No. of } \\
\text { Items }\end{array}$ & $\begin{array}{l}\text { Person- } \\
\text { separation Index }\end{array}$ \\
\hline Self-assessed language & 14 & .86 \\
competence & 7 & .45 \\
IC - Knowledge & 10 & .77 \\
IC - Skills & 10 \\
\hline
\end{tabular}

\begin{tabular}{|c|c|c|c|c|c|}
\hline Other Scales & No. of Items & Cronbach Alpha & Factor loadings & Item-total correlation & Total Variance explained \\
\hline $\begin{array}{l}\text { IC-Attitudes: } \\
\text { Willingness }\end{array}$ & 5 & .77 & .37 bis .83 & .39 bis .68 & \multirow{3}{*}{$53.9 \%$} \\
\hline IC - Atittudes: Affect 1 & 6 & .82 & .41 bis .81 & .45 bis .69 & \\
\hline IC - Atittudes: Affect 2 & 4 & .71 & .54 bis .74 & .44 bis. 59 & \\
\hline
\end{tabular}

Apart from the questions revolving around the students' IC, the questionnaire also contained questions about the language classes at the home school as well as the exchange program as such. The students were asked, for example, what aspects are important to their foreign language teacher in the foreign language classes (grammar, vocabulary, communication or pronunciation) or in what kind of activities they participated during their stay abroad (e.g., going to the movies, sightseeing, participating in a club, etc.), who they talked to in which language, etc. This data was examined by means of descriptive statistics as well as cluster analysis in order to detect patterns and generate variables on this basis.

\section{Analysis of covariance (ANCOVAs)}

For each target variable (each dimension of IC) two separate analyses of covariances (ANCOVA) were carried out for the posttest and the delayed posttest. The first ANCOVA included both the intervention and the control group. The main aim was to determine whether it plays a role for the learners' IC if they participated in an exchange activity or not. The second ANCOVA only involved the intervention group and analyzed which demographic, school-related and study abroad-related variables contribute to the explanation of the students' IC at the time of the posttest and delayed posttest. The values of the target variable at the time of the pretest were considered as covariables for these analyses. In this way, the participants' starting conditions were controlled for.

The analyses of the posttest data demonstrate what short-term effects exchange activities have (short-term effect). The analyses of the delayed posttest data demonstrate what effects they have in the longer run (long-term effects). The following variables were considered as possible explanatory variables: gender, parents' educational background, linguistic background, nationality, age, previous stays abroad, previous exchange activities, previous residence in TL area, type of program, preparation, accommodation, duration, contact with TL speakers, use of TL, activities undertaken during the stay, location.

For the posttest data the variables were selected on the basis of the p-value by means of backwards stepwise elimination. For the delayed posttest data, a more elaborate analysis technique was 
employed. The variables were selected on the basis of the Akaike information criterion (AIC). Since this usually yields models that are too comprehensive including non-significant variables, the BIC criterion was subsequently used to continue the variable selection. Furthermore, a ten-fold forward cross-validation was used to prevent overfitting and to get a more realistic estimation of prediction errors (Hastie, et al., 2009).

The analyses were done in SPSS 21 und R 3.0.2.

\section{Results}

\section{Short-term effect of exchange activities}

Willingness to engage with people from another cultural background.

The ANCOVA of the posttest data across all participants showed that the learners' willingness to engage with people from another cultural and linguistic background is largely dependent on the extent to which they were willing to do so even before the exchange (see Table 3). Participating in an exchange activity also seems to affect learners' willingness to engage with people from another cultural background since students in the intervention group exhibited higher willingness than those in the control group. The same goes for students whose parents have a tertiary education. Furthermore, there is an interaction between teaching methodology and the linguistic background of the students. If, in the eyes of the students, the home teacher does not emphasize communication in the foreign language lessons, monolingual students are significantly less willing to engage with people from another cultural and linguistic background than multilingual students. If the teacher emphasizes communication, monolingual and multilingual students do not differ. It is primarily the monolingual students, consequently, whose willingness to engage with people from other cultural and linguistic backgrounds profits from foreign language lessons that emphasize communication and interaction.

Table 3: Short-term effects on willingness (intervention and control group)

\begin{tabular}{lll}
\hline & Regressions coefficient B & $p$ \\
\hline Intercept & 4.571 & .000 \\
Control group & -1.609 & .000 \\
Willingness pretest & .612 & .000 \\
Parents' educational background: no tertiary education & -.981 & .000 \\
monolingual & -.154 & .528 \\
FL lessons: communication unimportant & & .490 \\
Linguistic background*FL lessons & .391 & .027 \\
\hline $\mathrm{R}^{2}=.50$ & & -1.754 \\
\hline
\end{tabular}

The analysis of the intervention group alone yields a similar picture. The best predictor of the participants' willingness to engage with people from the TL area shortly after their return home, is 
their willingness to do so before departure. Students whose parents have a tertiary education and multilingual students exhibit a stronger willingness to engage with people from the TL area. Besides this, some exchange-related variables could also be shown to play a role. The more often the participants used the TL during their stay, the higher their willingness to engage with people from the TL area after their return. Similarly, this willingness is higher among participants who reported having spoken regularly to the teachers of the partner school/language school than among those who reported doing this irregularly or never (see Table 4).

Table 4: Short-term effects on willingness (intervention group)

\begin{tabular}{lll}
\hline & Regression coefficient B & $p$ \\
\hline Intercept & 3.501 & .000 \\
Willingness T1 & .558 & .000 \\
Parents' educational background: no tertiary education & -.951 & .000 \\
monolingual & -.524 & .045 \\
Use of TL & .030 & .000 \\
No contact with teachers of partner / language school & -.830 & .004 \\
\hline R2=.45 & &
\end{tabular}

Intercultural attitudes: affect.

The more positive the students' attitudes towards representatives of the host culture were at the time of the pretest, the more positive they also were at the time of the posttest. So, once again the students' starting conditions play a crucial role. Besides this, the interaction between group membership (intervention or control group) and the parents' educational background plays a role (see Table 5). While in the control group students whose parents have a tertiary education are characterized by significantly more positive attitudes towards representatives of the host culture, the educational background of the parents does not play a role in the intervention group. It seems, consequently, that, in particular, students whose parents do not have a tertiary degree profit from exchange activities in terms of attitudes.

Table 5: Short-term effects on intercultural attitudes (intervention and control group)

\begin{tabular}{lll}
\hline & Regression coefficient B & $p$ \\
\hline Intercept & 5.265 & .000 \\
Control group & -.613 & .205 \\
Attitudes: Affect pretest & .629 & .000 \\
Parents' educational background: no tertiary education & -.545 & .079 \\
$\begin{array}{l}\text { Group membership (intervention vs control } \\
\text { group)*Parents' educational background }\end{array}$ & -2.076 & .021 \\
\hline R2=.48 & &
\end{tabular}


In the analysis of the intervention group alone, the affective starting conditions of the participants also emerged as the most important explanatory factor. In addition, the amount of use of the TL and regular contact with TL speakers were once again relevant. The more the students used the TL during their stay, the more positively disposed they are towards representatives of the host culture after their return. Regular contact with work colleagues or superiors has a positive effect on the students' intercultural attitudes. Finally, it turned out to be relevant for the students' intercultural attitudes what kind of study abroad program the students were involved in. Those students who did an internship or voluntary work during their stay had less positive intercultural attitudes after their return than those who participated in another kind of program (attending a partner/language school, working as an aupair, etc.) (see Table 6).

Table 6: Short-term effects on intercultural attitudes (intervention group)

\begin{tabular}{llr}
\hline & Regression coefficient B & $\mathrm{p}$ \\
\hline Intercept & 3.324 & .000 \\
Attitudes: Affect pretest & .667 & .000 \\
Kind of program: no internship /no voluntary work & 1.211 & .009 \\
No contact with work colleagues / superiors & -1.118 & .005 \\
$\mathrm{R}^{2}=.42$ & &
\end{tabular}

Intercultural skills.

With regard to the intercultural skills of the participants, the analysis of the posttest data also shows that it makes a difference whether students participated in an exchange activity or not. The students in the intervention group are interculturally significantly more skilled than those in the control group. Gender also plays a role here. In the control group males report significantly higher intercultural skills than females. In the intervention group males and females differ less and it is the females who report higher intercultural skills. Once more, the starting conditions of the participants play a crucial role since the intercultural skills at the time of the pretest turn out to be the best predictor of the intercultural skills at the time of the posttest (see Table 7).

Table 7: Short-term effects on intercultural skills (intervention and control group)

\begin{tabular}{llc}
\hline & Regression coefficient B & $\mathrm{p}$ \\
\hline Intercept & .697 & .000 \\
Control group & -.859 & .000 \\
Intercultural skills pretest & .590 & .000 \\
$\quad$ Girls & .217 & .092 \\
Group membership (intervention vs control group)*Gender & -.977 & .000 \\
$\mathrm{R}^{2}=.55$ & &
\end{tabular}

A look at the intervention group alone reveals that apart from the participants' starting conditions a 
number of exchange-related and teaching-related variables play a role. The more the students who participated in an exchange activity report having used the TL during their stay, the higher their intercultural skills shortly after their return. The duration of the stay also plays a role. A longer stay tends to have a positive effect. Those participants who only stayed in the host culture for one to two weeks exhibit the lowest values. This group only differs significantly from the group of students who stayed in the host culture for five to six weeks, however. Somewhat surprisingly, this latter group had the highest intercultural skills, even though they did not significantly differ from the group of students who was away for more than six weeks. Consequently, we can see a U-shaped development here where students with a medium length of stay seem to profit most and both students with a shorter and longer duration of stay are characterized by lower intercultural skills.

Once again regular contact with the teacher(s) of the partner school or language school also exerts a positive influence. But the teacher(s) at the local school also influence the intercultural skills of the exchange students. Students whose local FL teachers attach importance to communication and grammar have higher intercultural skills. Furthermore, the females in the intervention group report significantly higher intercultural skills then the males (see Table 8).

Table 8: Short-term effects on intercultural skills (intervention group)

\begin{tabular}{lll}
\hline & Regression coefficient B & P \\
\hline Intercept & .182 & .507 \\
Skills pretest & .541 & .000 \\
Use of TL & .010 & .000 \\
No contact with teachers of partner / language school & -.518 & .000 \\
Duration of stay: 1-2 weeks & -.172 & .344 \\
Duration of stay: 3-4 weeks & .087 & .621 \\
Duration of stay: 5-6 weeks & .314 & .143 \\
FL lessons: communication unimportant & -.438 & .015 \\
FL lessons: grammar unimportant & -.469 & .028 \\
Girls & .321 & .009 \\
\hline$R^{2}=.35$ & &
\end{tabular}

\section{Long-term effect of exchange activities}

In the last section we saw that students who left their home to work or study in another cultural environment for some time are significantly more interculturally competent upon their return than students who stayed at home. In this section we will analyse whether this positive effect of exchange activities lasts fairly long-term.

Willingness to engage with people from another cultural background. At the time of the delayed posttest, the learners' willingness to engage with people from another 
cultural and linguistic background and to learn something about them and their culture is still largely dependent on the extent to which they were willing to do so before the exchange. Still, the students who participated in an exchange are more willing to engage with people from another cultural and linguistic background than those who did not (see Table 9).

Table 9: Long-term effects on willingness (intervention and control group)

\begin{tabular}{lll}
\hline & Regression coefficient B & $\mathrm{p}$ \\
\hline Intercept & 3.192 & .000 \\
Willingness pretest & .576 & .000 \\
Intervention group & 1.022 & .002 \\
Parents' educational background: tertiary education & .678 & .008 \\
Boys & -.575 & .040 \\
Previous stays abroad: 0-2 times & -1.557 & .004 \\
Previous stays abroad: 3-5 times & -.390 & .394 \\
Previous stays abroad: 6-10 times & -.358 & .375 \\
Previous stays abroad: > 15 times & -.123 & .748 \\
Age: 16 years & -.032 & .922 \\
Age: $>16$ years & -.611 & .080 \\
$\mathrm{R}^{2}=.44$ & &
\end{tabular}

Apart from these two most dominant factors, a series of demographic variables also play a role. Students whose parents have a tertiary education and girls are significantly more willing to engage with people from another cultural background, students who are older than 16 years tend to be less willing to do so. Last but not least, the students' willingness to interact with people from another cultural background also depends on the number of times they have been abroad. Students, who have never been abroad, or only once or twice, are significantly less willing to engage interculturally.

A look at the intervention group alone confirms that the students' starting conditions are the most powerful explanatory factor for their willingness to engage with people from another cultural background three months after their return home. This is followed by the number of previous stays abroad, with students who have never been abroad, or only once or twice scoring significantly lower than the others. Next to this, a number of exchange-related variables could also be shown to be significant. The longer the students stayed in the host culture, the higher their willingness to engage with representatives of that culture three months after their return. An intensive contact with local people during one's stay also has a positive effect. Students who indicated having had weekly or daily contact with local students or work colleagues during their stay demonstrate a significantly higher willingness for intercultural engagement three months after their return than those who indicated having had less than weekly contact (see Table 10). 
Table 10: Long-term effects on willingness (intervention group)

\begin{tabular}{lll}
\hline & Regression coefficient B & $\mathrm{p}$ \\
\hline Intercept & 3.876 & .000 \\
Willingness pretest & .480 & .000 \\
Duration of stay: $3-4$ weeks & .277 & .422 \\
Duration of stay: 5-6 weeks & .554 & .317 \\
Duration of stay: more than 6 weeks & 1.732 & .000 \\
Previous stays abroad: $0-2$ times & -1.790 & .005 \\
Previous stays abroad: $3-5$ times & -.178 &. \\
Previous stays abroad: $6-10$ times & -.366 & .443 \\
Previous stays abroad: $>15$ times & -.014 & .974 \\
Regular contact with local students or work colleagues & .920 & .009 \\
\hline $\mathrm{R}^{2}=.39$ & & .34
\end{tabular}

Intercultural attitudes: affect.

How positively the students are disposed towards representatives of the TL culture three months after their return and how comfortable they feel among them largely depends on their affective dispositions before their departure. Next to this, the exchange experience itself also has an effect. The students in the intervention group are significantly more positively disposed towards representatives of the target culture than students in the control group and they feel significantly more comfortable among them (see Table 11).

Table 11: Long-term effects on intercultural attitudes (intervention and control group)

\begin{tabular}{lll}
\hline & Regression coefficient $\mathrm{B}$ & $\mathrm{p}$ \\
\hline Intercept & 1.593 & .001 \\
Intercultural attitudes pretest & .737 & .000 \\
Intervention group & 1.974 & .000 \\
\hline $\mathrm{R}^{2}=.53$ & &
\end{tabular}
$\mathrm{R}^{2}=.53$

The ANCOVA which only includes the intervention group demonstrates that, besides the affective starting conditions, the duration of stay has an influence on the students' intercultural attitudes three months after their return. The longer the stay in the target culture, the more positive the students' attitudes towards representatives of that cultural group are (see Table 12).

Table 12: Long-term effects on intercultural attitudes (intervention group)

\begin{tabular}{lll}
\hline & Regression coefficient B & $\mathrm{p}$ \\
\hline Intercept & 3.538 & .000 \\
Intercultural attitudes pretest & .694 & .000 \\
Duration of stay: $3-4$ weeks & .624 & .075 \\
Duration of stay: $5-6$ weeks & 1.094 & .049 \\
Duration of stay: $>6$ weeks & 1.546 & .002 \\
\hline $\mathrm{R}^{2}=.46$ & &
\end{tabular}


Intercultural skills.

With regard to the students' intercultural skills, the analysis across the intervention and the control group once again illustrates that participating in an exchange activity makes a difference not only shortterm but also long-term. At the time of the delayed posttest the students in the intervention group are interculturally significantly more skilled than the students in the control group. The most powerful explanatory variable, however, is once again the student's starting conditions, that is, their intercultural skills at the time of the pretest (see Table 13).

Table 13: Long-term effects on intercultural skills (intervention and control group)

\begin{tabular}{lll}
\hline & Regression coefficient $\mathrm{B}$ & $\mathrm{p}$ \\
\hline Intercept & -.351 & .013 \\
Intercultural skills pretest & .584 & .000 \\
Intervention group & 1.051 & .000 \\
$\mathrm{R}^{2}=.48$ & &
\end{tabular}

When looking at the intervention group in isolation, only the students' intercultural skills before the exchange could be shown to significantly predict their intercultural skill three months after their return (see Table 14).

Table 14: Long-term effects on intercultural skills (intervention group)

\begin{tabular}{lll}
\hline & Regression coefficient B & $\mathrm{p}$ \\
\hline Intercept & -.351 & .013 \\
$\mathrm{R}^{2}=.26$ & .543 & .000 \\
\hline
\end{tabular}

\section{Discussion and Conclusions}

The analyses across the intervention and control group consistently indicate that a stay in an area that is culturally and linguistically different from one's own has a positive influence on the development of one's IC. The most consistent finding in this study was that the students in the intervention group are interculturally more competent than those in the control group. They are more willing to engage with representatives of the target culture and to learn from and with them. They are also more positively disposed towards representatives of the target culture and have higher skills of discovery and interaction. Unlike in the study by Rexeisen, et al. (2008) this is not only true of the time shortly after their return home but seems to be a lasting asset as the analyses of the delayed posttest data show. Given that the vast majority of the exchange activities studied here were short term activities (one to six weeks), the study reinforces findings from other studies (Anderson, et al., 2006; Chieffo \& Griffith, 2004; Dwyer, 2004; Donnelly-Smith, 2009) which also demonstrate positive effects of shortterm programs on intercultural learning. This is an encouraging finding, particularly in light of the fact that short-term study abroad programs clearly dominate the field due to their more modest demands in terms of prior linguistic and cultural preparation, as well as financial resources (Engle \& Engle, 2003). Provided a number of factors that influence intercultural learning (see discussion below) are taken into account, short-term programs can be more than the 'vacation' as which they are sometimes decried (Donnelly-Smith, 2009).

As expected, the analyses also show that an exchange activity per se and of itself is not the key 
to successful intercultural development. The extent to which the participants can profit from an exchange experience depends on a number of factors. The affective starting conditions of the participants seem to be a major factor. The IC of the participants before the exchange always constituted the best predictor of their IC after the exchange. This is not surprising, as you would expect that students who are interculturally more competent before the exchange are also more competent after the exchange. Given the central role that students' starting conditions seem to play in their further development, it seems advisable to raise the students' awareness for their own expectations, attitudes and needs before they embark on an exchange. Raising awareness for their own starting conditions facilitates working on them and identifying areas for improvement. It is only once students are conscious of attitudes and expectations that negative attitudes can be improved and unrealistic expectations relativized. Some of the students' comments on the questionnaire suggest that there was little reflection on their part about their intercultural attitudes and skills. As one student put it "I never asked myself these questions before". 7 Another student said: "Actually I haven't given much thought to this yet". "It seems worthwhile that schools intensify student preparation in this area. Somewhat surprisingly, student preparation could not be shown to affect the participants' intercultural development. The questions relating to student preparation in the questionnaire focused on the provision of information on the place where the students would stay, on communicative norms and effective communication strategies and on potential communicative or cultural challenges. It is possible that the preparation of students for their intercultural experience should not necessarily or not exclusively focus on the provision of geographical, historical, cultural and linguistic information but rather on the students' expectations, attitudes and pre-existing skills.

While the results of our study suggest that even rather short exchange activities positively affect student's IC, they also show that the duration of stay is an important factor influencing ultimate success. With the exception of the students' intercultural skills, where a U-shaped development was identified, the data suggests that the longer the better. The longer the students stay in the target culture area, the more they seem to grow interculturally. This is a finding that is reinforced by many of the student comments in the questionnaire who lament that more time would be needed to really improve one's language and intercultural skills. The U-shaped developmental pattern found for the students' intercultural skills where students with a medium length of stay seem to profit most and both students with a shorter and longer duration of stay are characterized by lower intercultural skills also reflects previous research. It can potentially be accounted for by the fact that people who only stay in the host culture for a very short time have extremely limited opportunities to substantially develop interculturally. People who stay among people from the host culture for a longer time have more opportunities to really delve into everyday life there and encounter challenges or frustrations. While it is exactly such challenges or frustrations that forces study abroad students to develop interculturally (Ogay, 2000, pp. 274-277), they may also lead to a more cautious and, hence, lower assessment of their IC on the part of these students. What the findings certainly suggest is that a stay of one to two weeks is not particularly useful for the development of IC; since especially the group of participants who went on a one-to-two week exchange were less interculturally competent than the other groups. This

\footnotetext{
7 Translation by the authors. Original: "Au paravant je me suis jamais posé ces questions."

8 Translation by the authors. Original: "Eigentlich habe ich mir noch nicht so viele Gedanken gemacht."
} 
does not necessarily mean that several such rather short stays cannot have a long-term effect. Such short programs may also function as a door opener for further and longer studies abroad (Chieffo \& Griffith, 2004; Engle \& Engle, 2003). Nevertheless, exchange program coordinators/administrators should try to ensure a suitable duration of stay.

Furthermore, exchange programs or study abroad programs should foster regular contact with local people and promote active use of the TL through organisational structures (for example, living with a host family or individual exchange activities) as these two features have also proved relevant for the participants' IC following their return (Engle \& Engle, 2004, p.232). It seems likely that these two variables are indicative of a focused and reflective interaction with the host culture which is what ultimately separates a study abroad program from study at home and what most distinguishes different study abroad programs (Engle \& Engle, 2003, p. 4). A focused and reflective interaction with the host culture can be regarded as experiential learning where students truly experience the culture in which they reside (Anderson \& Lawton, 2011, p. 87). It may even be advisable to integrate such experiential learning components (e.g. local tandem partner, community service) as a compulsory element of exchange programs as in the AUCP program described by Engle and Engle (2004).

\section{Limitations}

The most notable limitation of this study is probably the fact that the questions on IC in our questionnaire were not equally meaningful for the intervention and the control group. Our decision to formulate group-specific items had the advantage that we would be sure that students in the intervention group would really report on their perceptions of and attitudes towards the group with which they were in contact. It also meant, however, that the students in the control group would also answer questions in relation to one particular group (e.g. Swiss Germans) which was randomly assigned. Consequently, they were answering questions about a group they had no contact with at that time and maybe never had contact with rather than answering questions in relation to foreigners in general. This very fact may have made some of the items difficult for them to answer as they would have to imagine how they would deal with people from that group, how much they like them or how comfortable they would feel among them. As far as the pretest is concerned, this is also true of the students in the control group since at that point they were not yet in contact with the group in question. Future research should investigate how closely related measures of a general IC and measures of a group-specific IC are and whether we can usefully assume that IC is a basic skill that is independent of the target group.

Another drawback of questionnaires on IC and of the construct of IC in general is that they, by definition, imply that there are clearly defined groups of people that somehow differ in terms of cultural habits and norms. Questions on norms, values, and habits of certain cultural groups necessarily homogenize that group and treat them as distinct entities. This bears the danger of stereotyping. It is questionable to what extent such a homogeneity and separateness of culture can realistically be assumed in the face today's extent of migration, increase of regional and global interconnectedness and the internal differentiation of modern societies where many people are multicultural and cannot be assigned to a specific culture.

Despite these limitations, the present study provides useful insights for study abroad program administrators, teachers and students thanks to a number of methodological merits, most notably the 
experimental design comprising an intervention and a control group, a pre-, post-, and delayed posttest, the large sample size, the fact that the participants were required to study abroad rather than choosing this option themselves, and the large range of types of programs that could be investigated.

\section{References}

Alexander, T. \& Perl, D. (2010). Chancen, Grenzen und Konsequenzen interkulturellen Lernens im internationalen Schüleraustausch. In Fachstelle für International Jugendarbeit der Bundesrepublike Deutschland e.V., (pp. 286-302). Bonn: Forum Jugendarbeit International.

Allport, G. W. (1954). The Nature of Prejudice. Cambridge/Reading, MA: Addison-Wesley.

Anderson, P. H., Lawton, L., Rexeisen, R. J., \& Hubbard, A. C. (2006). Short-term study abroad and intercultural sensitivity: A pilot study. International Journal of Intercultural Relations, 30(4), 457-469.

Anderson, P.H. \& Lawton, L. (2011). Intercultural Development: Study Abroad vs. On-Campus Study. Frontiers: The Interdisciplinary Journal of Study Abroad, 21, 86-108.

Andrich D., Sheridan B. \& Luo G. (2010) RUMM 2030: Rasch Unidimensional Measurement Models Software. Perth, Australia: RUMM Laboratory.

Baker, C. (1992). Attitudes and Language. Clevedon, Philadelphia \& Adelaide: Multilingual Matters.

Bennett, M. J. (1993). Towards ethnorelativism: A developmental model of intercultural sensitivity. In R. M. Paige (Ed.), Education for the intercultural experience. ( ${ }^{\text {nd }}$ ed., pp. 21-71). Yarmouth, ME: Intercultural Press.

Bennett, M. J., \& Hammer, M. R. (1998). The intercultural development inventory (IDI) manual. Portland, OR: The Intercultural Communication Institute.

Byram, M. (1997). Teaching and assessing intercultural communicative competence. Philadelphia: Multilingual Matters.

Chieffo, L., \& Griffiths, L. (2004). Large-Scale Assessment of Student Attitudes after a Short-Term Study Abroad Program. Frontiers: The Interdisciplinary Journal of Study Abroad, 10, 165-177.

Coleman, J. A. (1998). Language Learning and Study Abroad: The European Perspective. Frontiers: The Interdisciplinary Journal of Study Abroad, 4, 167-203.

Council of Europe (1982). Recommendation No. R(82) 18 of the Commitee of Ministers to Member States Concerning Modern Languages.

http://wcd.coe.int/com.instranet.InstraServet?command=com.instranet.CmdBlobGet\&Instran etImages $=6016308$ SecMode $=1 \&$ DocId $=676400 \&$ Usage $=2$

Crosbie, V. \& Sudhershan, A. (2009). Putting the Self into Assessment: evaluating linguistic and intercultural proficiency with LOLIPOP. In Zeynep Urkun (ed.) Issues in Assessing ESOL (pp. 817). International Association of Teachers of English as a Foreign Language

Deardorff, D. K. (2006). Identification and assessment of intercultural competence as a student outcome of internationalization. Journal of studies in international education, 10(3), 241-266.

Deutschschweizer Erziehungsdirektoren - Konferenz [D-EDK] (2013). Lehrplan 21. http:/ / konsultation.lehrplan.ch/

Donnelly-Smith, L. (2009). Global learning through short-term study abroad. Peer Review, 11(4), 12-15.

Dwyer, M. M. (2004). More Is Better: The Impact of Study Abroad Program Duration. Frontiers: The Interdisciplinary Journal of Study Abroad, 10, 151-163.

Dörnyei, Z., \& Csizér, K. (2005). The effects of Intercultural Contact and Tourism on Language Attitudes and Language Learning Motivation. Journal of Language and Social Psychology, 24(4), $327-$ 357.

Engle, L., \& Engle, J. (2003). Study abroad levels: Toward a classification of program types. Frontiers: The Interdisciplinary Journal of Study Abroad, 9, 1-20.

Engle, L., \& Engle, J. (2004). Assessing Language Acquisition and Intercultural Sensitivity 
Development in Relation to Study Abroad Program Design. Frontiers: The Interdisciplinary Journal of Study Abroad, 10, 219-236.

Fantini, A.E. \& Tirmizi, A. (2006). Exploring and assessing intercultural competence. World Learning Publications. Paper 1. Downloaded from http://digitalcollections.sit.edu/worldlearning publications/1/

Gardner, R. C. (1985). Social Psychology and Second Language Learning: The Role of Attitudes and Motivation. London: Edward Arnold.

Hammer, M. (2005). Assessment of the Impact of the AFS Study Abroad Experience. Executive Summary: Overall Findings. Downloaded from http://idiinventory.com/pdf/afs study.pdf

Hastie T., Tibshirani R. \& Friedman J. (2009). The Elements of Statistical Learning. 2nd ed. Springer Verlag.

Hewstone, M. (1996). Contact and Categorization: Social Psychological Interventions to Change Intergroup Relations. In C. N. Macrae, C. Stangor \& M. Hewstone (Eds.), Stereotypes and Stereotyping. (pp. 323-369). New York \& London: Guilford Press.

Ingram, D. E., \& O’Neill, S. (1999). Cross-Cultural Attitudes as a Goal of Language Teaching in the Global Context. Paper presented at the RELC Seminar Language in the Global Context: Implications for the Language Classroom. Singapore: Regional Language Center.

Kehl, K., \& Morris, J. (2008). Differences in Global-Mindedness between Short-Term and Semester-Long Study Abroad Participants at Selected Private Universities. Frontiers: The Interdisciplinary Journal of Study Abroad, 15, 67-79.

Leiprecht R. (2001). Internationale Schüler- und Jugendbegegnungen als Beitrag zur Förderung interkultureller Kompetenz. In Marianne Krüger-Potratz (Ed.). Interkulturelle Studien - iks Querformat (pp. 1-46). Münster: Arbeitsstelle Interkulturelle Pädagogik.

Leyens, J.-P., Yzerbyt, V., \& Schadron, G. (1994). Stereotypes and Social Cognition. London: SAGE Publications.

MacFarlane, A. (1997). Linguistic and Attitudinal Aspects of School-Year Group Exchanges: Immediate and longterm Outcomes for participants. Ottawa: University of Ottawa.

Masters G. (1982) A Rasch model for partial credit scoring. Psychometrika 47, 149-174

Medina-López-Portillo, A. (2004). Intercultural Learning Assessment: The Link between Program Duration and the Development of Intercultural Sensitivity. Frontiers: The Interdisciplinary Journal of Study Abroad, 10, 179-199.

Ogay, T. (2000). De la compétence à la dynamique interculturelles: Des théories de la communication interculturelle à l'épreuve d'un échange de jeunes entre Suisse romande et alémanique. Bern: Peter Lang.

Prechtl, E., \& Lund, A. D. (2007). Intercultural competence and assessment: Perspectives from the INCA Project. In H. Kotthoff \& H. Spencer-Oatey (Eds.). Handbook of Intercultural Communication, HAL 7. (pp. 467-490). Berlin, New York: Walter de Gruyter.

Rexeisen, R. J., Anderson, P. H., Lawton, L., \& Hubbard, A. C. (2008). Study Abroad and Intercultural Development: A Longitudinal Study. Frontiers: The Interdisciplinary Journal of Study Abroad, 17, 120.

Ruben, B.D. (1976). Assessing communication competency for intercultural adaptation. Group and Organization Studies, 1, 334-354.

Savicki,V., Downing-Burnettea, R., Hellerb, L., Binderb, F. \& Suntingerb, W. (2004). Contrasts, changes, and correlates in actual and potential intercultural adjustment. International Journal of Intercultural Relations, 28, 311-329.

Tarrant, M. A., Rubin, D. L., \& Stoner, L. (2014). The Added Value of Study Abroad: Fostering a Global Citizenry. Journal of Studies in International Education, 18(2), 141-161.

Van der Zee, K. I., \& Van Oudenhoven, J. P. (2000). The Multicultural Personality Questionnaire: A 
multidimensional instrument of multicultural effectiveness. European Journal of Personality, 14, $291-$ 309. doi 10.1002/1099-0984(200007/08)14.

Weier, U. (2009). Interkulturelles Lernen und Sprachbegegnung konkret - Schüleraustausch in der Grundschule. In C. Fäcke (Hrsg.), Sprachbegegnung und Sprachkontakt in europäischer Dimension. (pp. 141-168). Frankfurt a.M.: Peter Lang.

Williams, T. R. (2005). Exploring the impact of study abroad on students' intercultural communication skills: Adaptability and sensitivity. Journal of Studies in International Education, 9(4), $356-371$. 